\title{
A FORMAÇÃO DE CONSENSOS NA REALIZAÇÃO DE POLÍTICAS PÚBLICAS DE REGULARIZAÇÃO FUNDIÁRIA: A LEI 13.465/2017 E A GESTÃO DEMOCRÁTICA DAS CIDADES
}

\author{
CONSENSUS FORMULATION OF PUBLIC POLICY OF LAND REGULARIZATION: LAW 13.465 /2017 AND THE \\ DEMOCRATIC MANAGEMENT OF CITIES
}

\section{RESUMO}

A dinâmica do processo de urbanização das cidades brasileiras potencializou a formação de assentamentos informais urbanos. Assim, a partir da CRFB/88, com a edição de um capítulo próprio disciplinando a política pública urbana, surge um marco normativo para tratar da regularização fundiária. Após a promulgação do texto constitucional e a posterior edição de inúmeros atos normativos sobre o tema, ocorreu a consolidação de uma base jurídica e política sobre regularização fundiária. Todo o aparato normativo editado estava pautado em uma política de regularização pautada na participação popular, especialmente nos destinatários diretos da política pública. Tal afirmativa encontra amparo na Lei 10.257/2001 (Estatuto da Cidade); MP 2220/2001 (disciplina a concessão de uso especial para fins de moradia); Lei 10.406/2002 (Código Civil) e na Lei 11977/2009 (dispõe sobre regularização fundiária em imóveis da União). Essa legislação consolidou instrumentos de regularização fundiária, a partir de uma dinâmica de gestão democrática do espaço urbano. A edição da Lei 13465/2017 altera de forma substantiva a sistemática anterior, privilegiando uma regularização fundiária pautada na atuação independente da Administração Pública, sob o argumento da desburocratização. A opção legislativa é perceptível, a partir da revogação do artigo 48, inciso III da Lei 11.977/2009, afastando a exigência legal de participação democrática. A reflexão exposta no presente ensaio tem como perspectiva, verificar se a participação popular na formatação de políticas públicas de regularização fundiária ainda pode ser tida como mandatória diretamente por força do artigo $2^{\circ}$, inciso II da Lei 10.257/2001.

Palavras-chave: Política Pública. Regularização Fundiária. Participação popular. Gestão democrática.

\section{ABSTRACT}

The dynamics of the urbanization process of Brazilian cities has enhanced the formation of informal urban settlements. Thus, from the CRFB / 88, with the edition of its own chapter disciplining urban public policy, a normative framework emerges to deal with land regularization. After the promulgation of the constitutional text and the subsequent edition of numerous normative acts on the subject, there was the consolidation of a legal and political basis on land regularization. The entire normative apparatus edited was based on a policy of regularization based on popular participation, especially on the direct recipients of public policy. This statement is supported by Law 10.257 / 2001 (City Statute); MP 2220/2001 (disciplines the granting of special use for housing purposes); Law 10.406 / 2002 (Civil Code) and Law 11977/2009 (provides for land regularization in Union real estate). This legislation consolidated land regularization instruments, based on a dynamic of democratic management of urban space. The edition of Law $13465 / 2017$ substantially alters the previous system, favoring a land regularization based on the independent action of the Public Administration, under the argument of bureaucracy. The legislative option is noticeable from the repeal of article 48, item III of Law 11.977 / 2009, departing from the legal requirement for democratic participation. The reflection presented in this essay aims to verify if popular participation in the shaping of public policies for land regularization can still be taken as mandatory directly by virtue of article 2, item II of Law 10.257 / 2001.

Keywords: Política Pública. Regularização Fundiária. Participação popular. Gestão democrática.

\section{Rafael da Mota Mendonça a, b}

${ }^{a}$ Pontifícia Universidade Católica (PUCRio), Rio de Janeiro, RJ, Brasil

${ }^{\mathrm{b}}$ Universidade do Estado do Rio de Janeiro (UERJ), Rio de Janeiro, RJ, Brasil

DOI: 10.12957/geouerj.2019.48414

Correpondência: rafael.dm@uol.com.br

Recebido em: 18 set. 2019 Revisado em: 14 out. 2019 Aceito em: 12 dez.2019 


\section{INTRODUÇÃO}

Os conflitos urbanos no Brasil ganham protagonismo no campo jurídico no momento em que alcançam nível constitucional (Título VII, Capítulo II, da Constituição da República Federativa do Brasil - CFRB - de 1988). Embora essa problemática tenha causas históricas nos processos de industrialização e desindustrialização, acompanhados de um êxodo rural desordenado, a mesma nunca foi enfrentada como um tema estrutural na pauta política do país. A partir de 1988 com a promulgação da Constituição e posterior produção legislativa infraconstitucional, a questão urbana é levada ao centro das discussões.

A situação de informalidade dos diversos assentamentos urbanos tem conexão direta com a natureza jurídica da relação desses ocupantes com o bem ocupado. A proteção que o ordenamento jurídico outorga a esses ocupantes está no centro da problemática, tornando relevante para a compreensão geral do tema a análise da regularização fundiária com um dos pilares da política pública urbana.

O artigo 182 da CRFB/88 estabelece os parâmetros para o desenvolvimento de uma política urbana que atenda as demandas contemporâneas de regularização fundiária e urbanística e regulação do uso do solo. Para tanto, o texto consagra institutos de vanguarda, como plano diretor, função social da propriedade pública e privada, desapropriação com indenizações em dinheiro ou em títulos da dívida pública, parcelamento ou edificação compulsória, imposto sobre a propriedade predial e territorial urbana progressivo no tempo, usucapião especial urbana e a concessão de uso especial para fins de moradia.

A reboque de tais previsões constitucionais o legislativo brasileiro iniciou uma ampla produção normativa a fim de consagrar e regulamentar tais institutos. Ilustrando tal orientação, a Lei 10257 de 10 de julho de 2001 (Estatuto da Cidade) regulamentou os artigos 182 e 183 da CRFB/88, estabelecendo as diretrizes gerais da política urbana. O referido diploma disciplinou os instrumentos gerais para desenvolvimento de políticas urbanas, tais como o parcelamento, edificação ou utilização compulsórios; o IPTU progressivo no tempo; a desapropriação com pagamento em títulos da dívida pública; a usucapião especial de imóvel urbano; o direito de superfície; o direito de preempção; a outorga onerosa do direito de construir; as operações urbanas consorciadas; a transferência do direito de construir; o estudo de impacto de vizinhança; o plano diretor; e a gestão democrática da cidade.

A partir do marco regulatório estabelecido pelo Estatuto da Cidade, diversos diplomas seguiram o mesmo caminho, buscando instrumentalizar a atuação estatal no gerenciamento do ambiente urbano. É o que se percebe com a edição da Medida Provisória 2220 de 04 de setembro de 2001, que regulamenta a concessão de uso especial para fins de moradia, disciplinada no § 1ํ do art. 183 da CRFB/88; o Código Civil de 2002, que consagrou a função social da posse e da propriedade, a usucapião especial urbana e a autonomia entre os institutos da posse e da propriedade; a Lei 11481 de 31 de maio de 2007 que além de inserir a concessão de 
direito real de uso e a CUEM no rol de direitos reais (artigo 1225, XI e XII do Código Civil) e no rol de direitos que podem ser objeto de hipoteca (artigo 1473, VIII e IX do Código Civil), prevê medidas voltadas à regularização fundiária de interesse social em imóveis da União; e a Lei 11977 de 07 de julho de 2009 que dispõe sobre o Programa Minha Casa, Minha Vida e a regularização fundiária de assentamentos localizados em áreas urbanas, especialmente a partir do instituto da Legitimação de Posse.

A partir da legislação citada, percebe-se que a CRFB/88 inaugurou as bases para um desenvolvimento efetivo de políticas urbanas que atendam a realidade concreta brasileira. Chama a atenção os inúmeros instrumentos de regularização fundiária e de regulação do uso do solo urbano. Tal fato demonstra uma conformidade da legislação com a realidade urbana brasileira.

Essa produção normativa, a partir do marco constitucional, buscou solucionar a problemática decorrente do processo de urbanização das cidades brasileiras e a consequente produção de assentamentos informais. O conjunto normativo exemplificado demonstra um reconhecimento por parte do poder público da existência de um ambiente urbano segregado, a partir da predominância de ocupações irregulares, e da necessidade de incluí-las na lógica do direito formal.

Para tanto, a postura dos poderes constituídos, bem como das próprias organizações sociais deve realizar uma conformação entre os instrumentos de regularização fundiária previstos na legislação citada e os seus destinatários. Até a edição da Lei 11977/2009 é possível afirmar que o modelo de regularização adotado era um modelo pautado na participação da sociedade, instituindo uma gestão democrática da cidade.

A edição da Lei 13465, de 11 de julho de 2017 altera a sistemática da regularização fundiária. A referida lei revogou parte da Lei 11977/2009, instituindo uma estrutura de regularização fundada na transferência da propriedade e sob o argumento da desburocratização, não faz menção expressa ao chamamento popular na participação da construção dos pilares da política urbana, especialmente a de regularização fundiária.

Desta forma, o presente ensaio tem o objetivo de analisar a discricionariedade da Administração Pública na escolha da prioridade pública, no que tange ao desenvolvimento de políticas públicas urbanas de regularização fundiária. $O$ objetivo central da análise é ratificar a ideia de que a referida discricionariedade ganha legitimidade a partir da participação popular na escolha da prioridade pública. Além disso, será exposta a percepção de que a participação popular tem sua fonte direta no Estatuto da Cidade, não sofrendo qualquer interferência em razão da derrogação imposta pela Lei 13465/2017 à Lei 11977/2009.

Políticas públicas urbanas: Discricionariedade da Administração Pública na escolha da prioridade pública 
No que tange a formulação das políticas públicas, especialmente políticas de regularização fundiária e urbanística, registra-se que é competência de o Poder Executivo definir o interesse público. Para tanto, devese levar em conta critérios de conveniência e oportunidade e os parâmetros definidos pela legislação constitucional e infraconstitucional, além da vontade dos destinatários da política pública. Trata-se de ato discricionário cujos motivos e objetos são definidos estritamente, na estrutura institucional do Estado Brasileiro.

Sobre o conceito de Poder Discricionário, José dos Santos Carvalho Filho assevera que "é a prerrogativa concedida aos agentes públicos de elegerem, entre várias condutas possíveis, a que traduz maior conveniência e oportunidade para o interesse público ${ }^{1 "}$.

Neste sentido, a opção pela regularização fundiária e urbanística de assentamentos informais em solo urbano de acordo com o novo contexto jurídico-institucional, encontra respaldo legal na Constituição Federal, atendendo ao princípio da dignidade da pessoa humana (Art. 1으, inciso III da CF); contribui para cumprimento de um dos objetivos fundamentais da República Federativa do Brasil, a erradicação da pobreza e da marginalização e redução das desigualdades sociais e regionais (Art.3o, inciso III da CF); o cumprimento da função social da propriedade (Art. 5ㅇ, inciso XXIII da CF); o atendimento ao direito social à moradia (Art. 60 da CF); e o disposto no capítulo da Política Urbana (Arts. 182 e 183).

Diante do quadro social alarmante relacionado ao déficit habitacional no Brasil, bem como todas as previsões legais, políticas e programas governamentais, tornam-se extremamente contraditórias opções administrativas que privilegiam o remanejamento de moradores de ocupações urbanas consolidadas².

A diretriz da política urbana é conhecer, zelar e garantir que os imóveis urbanos, públicos ou particulares, cumpram sua função socioambiental. Desta forma, o norte da atuação estatal é a implementação de políticas voltadas para um novo modelo de desenvolvimento econômico e social, baseado na inclusão socioterritorial e no fomento ao desenvolvimento sustentável.

\footnotetext{
${ }^{1}$ CARVALHO FILHO, José dos Santos. Manual de Direito Administrativo. 21a Ed. Rio de Janeiro: Lumem Juris, 2008. P. 47.

2 De acordo com o Ministério das Cidades (2010), o déficit habitacional no Município do RJ é de 220.774 domicílios; no Estado do RJ de 515.067 domicílios; no Brasil chega ao patamar de 6,940 milhões de unidades (85\% na área urbana); e na América Latina (Programa das Nações Unidas para os Assentamentos Humanos, 2000) de 51 milhões. Em oposição a esses números, o Brasil soma uma marca de 7,906 milhões de imóveis vagos, 80,3\% em áreas urbanas (IBGE - 2010)Dados divulgados pelo Centro de Estatística e Informações da Fundação João Pinheiro e pela Secretaria Nacional de Habitação do Ministério das Cidades, em 19 de dezembro de 2013. Disponível em http://www.fjp.mg.gov.br/index.php/noticias-em-destaque/2680-fundacao-joao-pinheiro-e-ministerio-dascidades-divulgam-os-resultados-do-deficit-habitacional-municipal-no-brasil. Acesso em 10 de dezembro de 2015. A metodologia utilizada considera como integrante do déficit habitacional qualquer domicílio amostrado em que ocorre uma das quatro situações: habitação precária (domicílios improvisados ou rústicos - A carência de infraestrutura urbana foi o componente de inadequação que mais afetou os domicílios urbanos brasileiros. No total, 13 milhões de habitações (26,4\%) careciam de pelo menos um item de infraestrutura básica: água, energia elétrica, esgotamento sanitário ou coleta de lixo.), coabitação familiar (soma dos cômodos e das famílias conviventes com intenção de construir um domicílio exclusivo), ônus excessivo de aluguel (superior a 30\% da renda familiar) ou adensamento excessivo de moradores em imóveis alugados (mais de três moradores por dormitório)
} 
Outra diretriz igualmente importante é garantir que a regularização fundiária ocorra de forma articulada com a regularização urbanística e ambiental, o que viabiliza o ordenamento espacial, impedindo o adensamento do território. Nessa linha, os órgãos públicos de patrimônio devem implementar políticas públicas de habitação de acordo com os termos disciplinados na CRFB/88. Maria Paula Dallari Bucci enfrentando o tema da política de desenvolvimento urbano como política pública, afirma que

a política pública visa atingir objetivos sociais em tempo e quantidade previamente determinados. É um conjunto de medidas coordenadas com objetivo de impulsionar a máquina governamental para realizar um objetivo de ordem pública (...). São arranjos complexos típicos da atividade políticoadministrativa $(\ldots)^{3}$.

Diante do conceito apresentado, importante ressaltar que não se trata de uma política de governo e muito menos de uma política de Estado. A hipótese em análise aborda de forma ampla a atuação do Poder Executivo na consolidação de política com conteúdo pragmático direto e imediato, garantindo e consagrando os objetivos essenciais da república brasileira.

Política pública é o espaço que o Estado tem de discricionariedade para cumprimento de prestações positivas exigidas pela CRFB/88 e legislação complementar. Tal discricionariedade deve levar em conta critérios de conveniência e oportunidade, além da vontade dos destinatários da política pública.

É conhecida a tradicional discussão e abordagem acerca do controle judicial das políticas públicas, com a ferrenha critica do ativismo judicial de promotores e juízes. Assim, intervenções realizadas durante a elaboração de projeto de regularização fundiária, tanto pelo Poder Judiciário, quanto pelo Poder Legislativo, são hipóteses de ativismo, impedindo, assim, que propostas de regularização fundiária sejam apreciadas e implementadas pelos órgãos competentes.

O controle de políticas públicas pelo Judiciário e pelo Legislativo, é realizado em caráter excepcional. É sabido que não é função desses Poderes a formulação dessas políticas, papel essencial do Executivo, restando apenas o controle de sua legalidade. Maria Paula Dallari Bucci conceitua política pública a partir dessa lógica de discricionariedade do Poder Executivo:

Política pública é o programa de ação governamental que resulta de um processo ou conjunto de processos juridicamente regulados visando coordenar os meios a disposição do Estado para realização de objetivos socialmente relevantes e politicamente determinados. Como tipo ideal a política pública deve visar a realização de objetivos definidos, expressando a seleção de prioridades, a reserva dos meios necessários a sua consecução e o intervalo de tempo em que se espera o atingimento dos resultados ${ }^{4}$ (grifos nossos).

\footnotetext{
${ }^{3}$ BUCCl, Maria Paula Dallari (Organizadora). Políticas Públicas: reflexões sobre o conceito jurídico. O Conceito de Política Pública em Direito. 1a Ed. São Paulo: Saraiva, 2006. P. 23.

4 BUCCl, Maria Paula Dallari. Ob. Cit. 2006. P. $40-41$.
} 
De acordo com o conceito apresentado, é certo que para uma política pública gozar de legitimidade não basta sua conformação com o ordenamento jurídico e o cumprimento das normas do programa pré-definidos, mas sim, que venha a atingir interesses sociais relevantes, consagrando os preceitos tutelados pela CRFB/88. Assim, não restam dúvidas de que política pública habitacional tem que ser desenvolvida no interesse público e de acordo com os anseios da sociedade. A seleção de prioridades na disponibilidade do patrimônio público é realizada pelo Executivo levando em conta o seu reflexo substantivo no meio social.

Abordando a questão dos reflexos da política pública na vida da população, bem como a escolha de prioridades, é elucidativa a afirmação de Maria Goretti Dal Bosco:

A prestação de serviços públicos de qualidade, como meta final da atuação da administração pública, só pode se concretizar na medida em que o cidadão passa a ser ouvido em suas expectativas e, com isso, torna-se integrante dos mecanismos que configuram as determinações do interesse público. Logo, a aproximação da administração pública com os cidadãos deveria ser o objetivo fundamental das estruturas de governo 5 .

Imprescindível destacar, dentro da perspectiva de política pública exposta, que a eleição das prioridades deve respeitar a efetivação dos direitos fundamentais e sociais. A regularização fundiária de assentamentos urbanos irregulares, como instrumento de política pública, é um exemplo de escolha de prioridade realizada pelo Poder Executivo.

Além da análise da implementação das políticas públicas sob a ótica da consagração dos direitos fundamentais, imprescindível sua análise a partir do contexto de direito à cidade, instituído pela Lei n. 10.257 de 2001, Estatuto da Cidade. Essa nova lógica impõe ao Estado a concretização de políticas de inserção de todo cidadão nesse novo contexto de cidade, garantindo a moradia a partir da regularização fundiária. Confirase o que afirma Maria Garcia sobre políticas públicas da cidade:

Desde que, portanto, a Cidade surge como um projeto de vida em comum a ordem social (a felicidade, como visto em Kelsen), necessário delimitar políticas públicas - "metas coletivas conscientes" (Hugo Assman) - nesse mesmo sentido de delimitação, isto é, dentre as várias necessidades coletivas aquelas que serão priorizadas pelo Poder Público para atendimento, é dizer, necessidades públicas; a serem atendidas pelo esforço de toda a sociedade ${ }^{6}$.

Para cumprimento dos termos do Estatuto da Cidade e o pleito por uma cidade inclusiva, a escolha de prioridades realizadas pelo Executivo deve atender ao núcleo essencial do direito fundamental à moradia. 0 artigo 182 da CRFB/88 disciplina o princípio básico que orienta todas as políticas públicas urbanas, a função social das cidades. O dispositivo constitucional é regulamentado pelo artigo 20 do Estatuto da Cidade, que determina os objetivos da política urbana. Analisando esse dispositivo, Rosangela Marina Luft destaca:

\footnotetext{
${ }^{5}$ DAL BOSCO, Maria Goretti. Discricionariedade em políticas públicas. Capítulo III. Curitiba: Juruá, 2008. P. 252.

${ }^{6} \mathrm{GARCIA}$, Maria (Org.). A Cidade e seu Estatuto. A Cidade e o Estado, Políticas Públicas e o Espaço Urbano. Capítulo 2. 1a Ed. São

Paulo: Editora Juarez de Oliveira, 2005. P. 27.
} 
O artigo 2ㅇ do Estatuto da Cidade, ao estabelecer as diretrizes gerais ao exercício das ações urbanísticas, reforça que todas têm idêntico escopo acrescenta à função social da cidade o princípio da função social da propriedade. São eles, portanto, a nascente principiológica que delineia tanto as atividades dos poderes públicos nas esferas federal, estadual, distrital e municipal, quanto às atitudes dos particulares em quaisquer questões que se refiram ao uso e ocupação do solo e à urbanização dos espaços e assentamentos urbanos. No que diz respeito ao princípio da função social da cidade, não há (ainda) uma cultura jurídica solidificada. As abordagens mais frequentes a respeito da cidade e da urbanificação partem do âmbito patrimonial individual, este enquanto esfera de direitos dotada de determinados limites que autorizam a ingerência do Estado em prol do interesse público (...). No Brasil o princípio da função social da cidade foi inaugurado expressamente em texto constitucional no ano de 1988 e, desde então, possui esparsas teorizações no ambiente jurídico. Trata-se de uma baliza precursora da ação estatal que deve servir de referência na adequação e implementação de políticas municipais de urbanificação, mas que demanda o estabelecimento de alguns marcos acerca do seu conteúdo7.

As políticas públicas de desenvolvimento urbano devem estar amparadas nesse princípio. Assim, a postura do gestor público deve consagrar os elementos contemporâneos formadores das cidades em ampla convergência com os preceitos constitucionais e legais citados.

Seguindo os diversos encontros internacionais de discussão acerca da cidade, tratados, declarações e cartas, alguns elementos formadores da função social das cidades, devem ser respeitados, entre eles: habitação, trabalho, lazer, circulação, planejamento urbano, mínimo existencial, gestão democrática, urbanização enquanto função pública, sustentabilidade ambiental e descentralização das políticas ${ }^{8}$. Os órgãos públicos de patrimônio devem balizar as políticas urbanas, especialmente as que estão relacionadas com a regularização fundiária, a partir desses elementos formadores.

A decisão do ente público no sentido de garantir a regularização fundiária de assentamentos informais, representa o legítimo exercício de uma competência constitucional, outorgada ao Executivo por força dos arts. $3^{\circ}, \mathrm{III}, 23, \mathrm{X}$ e 183, p. $1^{\circ}$, in fine, da $\mathrm{CRFB} / 88$, sendo, portanto, temerário outros Poderes imiscuírem-se no mérito das políticas públicas de regularização fundiária, sob pena de afrontar o princípio da separação e independência dos poderes.

\section{A formação de consensos na formulação de políticas públicas urbanas de regularização fundiária: 0 princípio democrático e a Lei 13465/2017}

\footnotetext{
7 LUFT, Rosangela Marina. Políticas Públicas Urbanas: Premissas e condições para efetivação do Direito à Cidade. Parte II, Capítulo I A cidade enquanto direito à função social. 1ạ Ed. Belo Horizonte: Editora Fórum, 2011. P.112.

8 OSÓRIO, Letícia Marques. Direito à Moradia adequada na América Latina. In: FERNANDES, Edésio; ALFONSIN, Betânia. Direito à moradia e segurança da posse: diretrizes, instrumentos e processo de gestão. 1ạ Ed. Belo Horizonte: Fórum, 2004. P. 31 - 32 . A autora cita alguns diplomas internacionais que consagram o direito à cidade e seus elementos formadores: Declaração Universal dos Direitos do Homem (1948); pacto Internacional de Direitos Sociais, Econômicos e Culturais de 1966; Convenção Internacional sobre a eliminação de todas as formas de discriminação racial de 1965, Declaração sobre raça e preconceito racial de 1978; Declaração sobre Assentamentos Humanos de Vancouver de 1976; Agenda 21 sobre Maio Ambiente e Desenvolvimento de 1992; Carta Social Europeia, revisão de 1996; Agenda Habitat de 1996; e os Comentários gerais ns. 04 e 07 do Comitê das Nações Unidas de Direitos Econômicos, Sociais e Culturais.
} 
A Administração Pública deve realizar projetos de regularização fundiária de acordo com o contexto institucional e jurídico pautado pela Lei 10.257/2001; Lei 11.448/2007; Lei 11.977/2009; CC/2002; CRFB/88 e Lei 13465/2017. Até a edição desta última norma, a regularização fundiária deveria ser articulada com a regularização urbanística e ambiental, além de ser fruto de uma convergência de ideias (formação de um consenso) entre o Executivo e os destinatários da política pública.

Os projetos de regularização fundiária devem ser desenvolvidos com o objetivo de permitir a inclusão socioterritorial de ocupantes de assentamentos informais, com ordenamento espacial e delimitação de território, a partir de normas urbanísticas que permitam preservar o ordenamento adotado e controlar o adensamento do espaço cedido à comunidade, sempre na tentativa de preservar ao máximo a ocupação original, realizando realocações apenas na hipótese de risco para o morador.

Um dos critérios mais relevantes observados na elaboração de projetos de regularização fundiária é a participação efetiva dos moradores, destinatários dessa política, com ampla formação de um consenso entre todos os atores envolvidos. O Executivo, responsável pela formulação de políticas de desenvolvimento urbano, seguindo os termos da CRFB/88 e legislação infraconstitucional, deve formular projetos de regularização de acordo com as necessidades apresentadas pelos próprios moradores. Dessa forma, os critérios técnicos deverão respeitar questões sociais, culturais, históricas e ambientais.

O projeto de regularização fundiária, como instrumento de política pública urbana, deve ser fruto de uma convergência de vontades e interesses específicos. Isso demonstra a participação efetiva do cidadão na formulação de políticas públicas, consagrando o princípio democrático presente em grande parte da legislação urbanística. Nessa linha, o Estatuto da Cidade em seu artigo 2º, incisos I, II, III, IV e XIV, disciplinando as diretrizes gerais da política urbana, determina que:

\begin{abstract}
Art. 2o A política urbana tem por objetivo ordenar o pleno desenvolvimento das funções sociais da cidade e da propriedade urbana, mediante as seguintes diretrizes gerais: I - garantia do direito a cidades sustentáveis, entendido como o direito à terra urbana, à moradia, ao saneamento ambiental, à infraestrutura urbana, ao transporte e aos serviços públicos, ao trabalho e ao lazer, para as presentes e futuras gerações; II - gestão democrática por meio da participação da população e de associações representativas dos vários segmentos da comunidade na formulação, execução e acompanhamento de planos, programas e projetos de desenvolvimento urbano; III - cooperação entre os governos, a iniciativa privada e os demais setores da sociedade no processo de urbanização, em atendimento ao interesse social; IV - planejamento do desenvolvimento das cidades, da distribuição espacial da população e das atividades econômicas do Município e do território sob sua área de influência, de modo a evitar e corrigir as distorções do crescimento urbano e seus efeitos negativos sobre o meio ambiente; XIV - regularização fundiária e urbanização de áreas ocupadas por população de baixa renda mediante o estabelecimento de normas especiais de urbanização, uso e ocupação do solo e edificação, consideradas a situação socioeconômica da população e as normas ambientais (grifos nossos).
\end{abstract}

Seguindo as diretrizes apresentadas, especialmente no inciso II, que prevê a gestão democrática por meio da participação da população na formulação, execução e acompanhamento dos projetos de desenvolvimento urbano, é possível afirmar que a política pública urbana deve ser resultado de um consenso. 
A atuação estatal deve ser balizada, sempre dentro de critérios técnicos, pelas demandas dos destinatários da própria política pública a ser realizada.

Nessa linha, a Lei 11.977, de 07 de julho de 2009, dispõe sobre o Programa Minha Casa, Minha Vida e a regularização fundiária de assentamentos localizados em áreas urbanas, disciplinava em seu artigo 48, III que os destinatários da regularização fundiária deveriam participar de todas as etapas desse processo ${ }^{9}$. inciso III, revogado pela Lei 13465/2017, apresentava como parâmetro para a elaboração dos projetos de regularização fundiária a participação dos interessados em todas as etapas do processo, demonstrando a preocupação com a efetiva participação popular na formulação das políticas públicas.

A Lei 13465/2017 modificou quatro regimes jurídicos instituídos nas últimas décadas: (i) Regularização fundiária rural; (ii) Regularização fundiária urbana; (iii) Regularização fundiária no âmbito da Amazônia Legal; e (iv) Regime sobre os imóveis da União em especial sobre o regramento da alienação de imóveis da União. A referida Lei foi regulamentada pelo Decreto 9.310, de março de 2018.

O antigo marco legal de regularização fundiária, Lei 11977/2009, é Lei Federal, portanto, só disciplinava a regularização fundiária em áreas da União. Já a Lei 13465/2017 é Lei nacional, disciplinando a regularização fundiária em bens públicos de todos os entes da federação.

A Lei 13465/2017 desconstruiu o arcabouço jurídico existente acerca da regularização fundiária, especialmente a urbana. O regramento anterior estava consolidado nos seguintes pilares: (i) Lei 6766/79, que disciplina o parcelamento do solo em todo o território nacional; (ii) CRFB/88, que introduz o capítulo próprio da Política Urbana; (iii) Lei 10.251/2001 (Estatuto da Cidade), que regulamenta os artigos da Constituição sobre política pública urbana; e (iv) Lei 11.977/09, considerada até então o mais importante instrumento jurídico a tratar da matéria da regularização fundiária urbana.

A Lei 13465/2017 revogou os seguintes dispositivos: (i) Parte da Lei 6.015/1973; Parte da Lei 6.766/79 (Parcelamento do solo urbano); e o Capítulo III da Lei 11.977/2009.

Com as revogações indicadas e o tratamento outorgado aos institutos da regularização, o novo marco legal impõe uma inversão da lógica da política urbana. A dinâmica consolidada no ordenamento jurídico nacional nesse campo desde a $\mathrm{CRFB} / 88$, era pautada pelo respeito aos seguintes princípios: (i) Moradia digna; (ii) Função social da posse, propriedade e da cidade; (iii) Autonomia da posse frente a propriedade; (iv) Adequado ordenamento territorial; (v) Implantação de infraestrutura e garantia de áreas públicas; (vi) Participação da sociedade no desenvolvimento das políticas urbanas.

\footnotetext{
${ }^{9}$ Art. 48. Respeitadas as diretrizes gerais da política urbana estabelecidas na Lei no 10.257 , de 10 de julho de 2001, a regularização fundiária observará os seguintes princípios: III - participação dos interessados em todas as etapas do processo de regularização;
} 
A Lei 13465/2017 impõe uma inversão nessa lógica, a partir dos seguintes preceitos: (i) Competitividade; (ii) Eficiência energética; (iii) Complexidade funcional (art. 9o § $1^{\circ}$ ); (iv) Eficiência na ocupação e no uso do solo (art. 9 $\left.\S 1^{\circ}\right)$; e (v) Privilégio da proteção à propriedade e não a posse.

A nova Lei também deixa de disciplinar conceitos importantes para a regularização fundiária, como: (i) Área urbana consolidada; (ii) ZEIS - Zona Especial de Interesse Social; (iii) Etapas da regularização fundiária. Além disso, deixa de regulamentar mecanismo importante para a regularização fundiária, como o artigo 1.228, parágrafos 4ํ e 5o do Código Civil.

A partir da problematização apresentada a nova Lei pode inviabilizar o processo de regularização fundiária, uma vez que com a revogação do Capítulo 3 da Lei 11.977, dos art. 288-A a 288-G (Art. 73) que tratam do registro da regularização fundiária na Lei 6.015/73 e a inaplicabilidade de parte da Lei 6.766/79 (art. 57), quebra toda a lógica construída e consolidada no ordenamento jurídico pátrio. Além disso, o privilégio em disciplinar a questão proprietária, ignora o esforça teórico feito durante anos para garantir autonomia e o mesmo grau de importância aos institutos da posse e da propriedade.

Mesmo diante das alterações realizadas pela Lei 13465/2017, especialmente com a revogação do artigo 48, inciso III da Lei 11.977/2009, a participação popular na formatação de políticas públicas de regularização fundiária ainda pode ser tida como mandatória por força do artigo 2º, inciso II da Lei 10.257/2001, que legitima e institucionaliza a participação dos destinatários na formulação da política pública, dando, assim, substância e uma ambiência democrática à atuação do Poder Executivo.

A ordem jurídica contemporânea impõe uma perspectiva participativa em todas as esferas estatais, ou seja, em toda a atuação do poder público na solução dos conflitos concretos, especialmente na implementação de políticas públicas. O Estatuto da Cidade apresentou ao administrador público parâmetros que devem ser obedecidos nas práticas positivas do Estado. No que tange à participação popular, a gestão democrática das políticas urbanas é um desses parâmetros, em que a normatividade buscou aproximar o ente público da realidade concreta intensificando a legitimidade de suas políticas.

Habermas no seu trabalho sobre direito e democracia, entre facticidade e validade, faz uma construção sobre a participação do cidadão no processo legislativo como uma forma de dar legitimidade a atuação concreta da norma, deixando claro que toda essa sistemática se apoia no princípio da soberania popular. Segundo o autor, tal construção apresenta um paradoxo, uma vez que a legitimidade surge a partir da legalidade,

porque esses direitos dos cidadãos têm, de um lado, a mesma estrutura de todos os direitos, os quais abrem ao indivíduo esferas da liberdade de arbítrio. Mesmo sem levar em conta as diferenças nas modalidades de uso desses direitos, os direitos políticos também devem e podem ser interpretados como liberdades de ação subjetivas, as quais simplesmente fazendo do comportamento legal um dever, 
portanto, liberam os motivos para um comportamento conforme as regras. De outro lado, o processo legislativo democrático precisa confrontar seus participantes com as expectativas normativas das orientações do bem da comunidade, porque ele próprio tem que extrair sua força legitimadora do processo de um entendimento dos cidadãos sobre regras de sua convivência ${ }^{10}$.

Nesses termos, a atuação estatal será pautada a partir de regras que foram formuladas pela atuação dos titulares dos direitos políticos e devem balizar a sua própria atuação naquela comunidade, especialmente a gestão democrática. As legislações urbanísticas infraconstitucionais bem como o capítulo de política urbana da CRFB/88 são uma consequência do Fórum Nacional de política urbana que realizou encontros em todo o país na década de 1980. A agenda do pensamento da política urbana nesse período foi caracterizada por uma ampla produção acadêmica e participação dos movimentos sociais, que influenciaram e pautaram a produção legislativa urbanística ${ }^{11}$.

Os parâmetros da legislação foram fixados a partir de demandas formuladas pela própria população, demonstrando a conformação de um processo legislativo democrático. Desta forma, a base legislativa da política pública urbana é pautada de legitimidade, atendendo, assim, a realidade concreta e satisfazendo as expectativas dos destinatários dessa política.

A participação popular está positivada, tornando a norma um verdadeiro fruto de construção coletiva e democrática. A população participa da elaboração dos termos da lei e essa lei garante a participação da própria população na formulação e implementação de políticas públicas, inclusive, na escolha da prioridade pública. O consenso outorga à decisão administrativa ampla legitimidade, blindando a atuação estatal de qualquer tipo de intervenção ou controle, sobretudo de outros poderes (Judiciário e Legislativo), salvo na hipótese de lesão a direito.

A legitimidade do direito positivo está no processo democrático imposto à produção normativa. As normas de direito urbanístico são fruto de um processo democrático de construção dos parâmetros da política urbana brasileira. Nestes termos, os destinatários da política pública devem ratificar a política pública, estabelecendo um consenso entre administradores e administrados ${ }^{12}$.

A imposição de uma política pela Administração Pública que está em desacordo com as demandas e a própria vontade dos destinatários, estaria em oposição à formação discursiva de consensos a partir de uma

\footnotetext{
10 HABERMAS, Jürgen. Direito e democracia: Entre facticidade e validade, Volume I. 2a Ed. Jürgen Habermas; tradução Flávio Bueno Siebeneichler. Rio de Janeiro: Tempo Brasileiro, 2003. P. 114 - 115.

${ }^{11}$ MARICATO, Ermínia. Impasses da Política Urbana no Brasil. 1a Ed. Rio de Janeiro: Editora Vozes, 2011. P. 117 - 120.

12 HABERMAS, Jürgen. Ob. cit. P. 122 - 127. De acordo com o autor: "certamente a fonte de toda a legitimidade está no processo democrático da legiferação; e esta apela, por seu turno, para o princípio da soberania do povo. Todavia, o modo como o positivismo jurídico introduz esse princípio não preserva o conteúdo moral independente dos direitos subjetivos - a proteção da liberdade individual (...) o contrato da sociedade faz prevalecer o princípio do direito, na medida em que liga a formação política da vontade do legislador a condições e um procedimento democrático, sob as quais os resultados que apareceram de acordo com o procedimento expressam per se a vontade consensual ou o consenso racional de todos os participantes".
} 
lógica procedimental. A coerção, através da força estatal, cria um ambiente em que as políticas públicas são despidas de legitimidade democrática, uma vez que a escolha da prioridade pública foi realizada pelo Executivo sem a convergência de vontades necessária, ou nos dizeres de Habermas, de uma vontade racional ${ }^{13}$.

O já citado artigo $2^{\circ}$, II do Estatuto da Cidade determina a participação popular na elaboração de projetos de desenvolvimento urbano e o inciso III impõe a cooperação entre os governos, iniciativa privada e os demais setores da sociedade no processo de urbanização, em atendimento ao interesse social, garantindo, assim, uma interlocução entre a sociedade e os próprios agentes do Estado.

No mesmo sentido o artigo 40 do Estatuto estabelece o plano diretor como o instrumento básico da política de desenvolvimento e expansão urbana. $O \S 4^{\circ}$ do referido dispositivo legal determina que no processo de elaboração do plano os poderes municipais deverão promover audiências públicas com a participação da população e de associações representativas dos vários segmentos da comunidade. Tal imposição demonstra a institucionalização na legislação infraconstitucional de veículos de diálogo que deverão lastrear a política pública urbana brasileira. $O$ diálogo entre os diversos órgãos do poder público e do próprio poder público com o cidadão está previsto em lei ${ }^{14}$.

As pretensões indicadas anteriormente são validadas a partir de argumentos comuns, ou seja, com uma força racionalmente motivadora, formando um consentimento apoiado em tomadas de posição recíprocas. Assim, a liberdade meramente subjetiva permite aos indivíduos sair do espaço público (espaço comunicativo) e tomar apenas uma posição de observação ${ }^{15}$. Desta forma, o princípio do discurso deve assumir, pela via da institucionalização jurídica, o papel de um princípio da democracia, legitimando a escolha da prioridade pública.

\footnotetext{
13 Ibid. P. 138 e 142. Segundo o autor: "Todavia, se discursos (e, como veremos, negociações, cujos procedimentos são fundamentados, discursivamente) constituem o lugar no qual se pode formar uma vontade racional, a legitimidade do direito apóiase, em última instância, num arranjo comunicativo: Enquanto participantes de discursos racionais, os parceiros do direito devem poder examinar se uma norma controvertida encontra ou poderia encontrar o assentimento de todos os possíveis atingidos. Por conseguinte, o almejado nexo interno entre soberania popular e direitos humanos só se estabelecerá, se o sistema dos direitos apresentar as condições exatas sob as quais as formas de comunicação - necessárias para uma legislação política autônoma podem ser institucionalizadas juridicamente". Na mesma linha, definindo o conceito de discurso racional, Habermas afirma que é "toda a tentativa de entendimento sobre pretensões de validade problemáticas, na medida em que ele se realiza sob condições da comunicação que permitem o movimento livre de temas e contribuições, informações e argumentos no interior de um espaço público constituído através de obrigações ilocucionárias. Indiretamente a expressão refere-se também as negociações, na medida em que estas são reguladas através de procedimentos fundamentados discursivamente".

${ }^{14} \mathrm{Art}$. 40. O plano diretor, aprovado por lei municipal, é o instrumento básico da política de desenvolvimento e expansão urbana. $\S 4$ ㅇ No processo de elaboração do plano diretor e na fiscalização de sua implementação, os Poderes Legislativo e Executivo municipais garantirão: I - a promoção de audiências públicas e debates com a participação da população e de associações representativas dos vários segmentos da comunidade; II - a publicidade quanto aos documentos e informações produzidos; III - o acesso de qualquer interessado aos documentos e informações produzidos.

15 Ibid. P. 156.
} 
A teoria do discurso aplicada nesse trabalho à política pública de desenvolvimento urbano outorga legitimidade às normas de ação em geral, que podem ser separadas em cinco categorias: (i) direitos fundamentais que resultam da configuração politicamente autônoma do direito à maior medida possível de iguais liberdades subjetivas de ação; (ii) direitos fundamentais que resultam da configuração politicamente autônoma do status de um membro em uma associação voluntária de parceiros do direito; (iii) direitos fundamentais que resultam imediatamente da possibilidade de postulação judicial de direitos e da configuração politicamente autônoma da proteção jurídica individual; (IV) direitos fundamentais à participação, em igualdade de chances, em processos de formação de opinião e da vontade, nos quais os civis exercitam sua autonomia política e através dos quais eles criam direito legítimo; e (v) direitos fundamentais a condições de vida garantidas social, técnica e ecologicamente, na medida em que isso for necessário para um aproveitamento, em igualdade de chances, dos direitos elencados anteriormente ${ }^{16}$.

No que tange a quarta categoria (direito fundamental à participação) são os próprios cidadãos que poderão avaliar se o direito que estão criando é legítimo. Os cidadãos têm a sua participação e possibilidade direta de influenciar na vontade do legislador institucionalizada. Assim, constitui-se um processo legislativo democrático, em que o cidadão influencia na elaboração da norma, Ihe outorgando legitimidade.

É o que ocorre na elaboração do plano diretor, uma vez que as audiências públicas, previstas no Estatuto da Cidade, têm o objetivo de permitir a participação do cidadão na formulação dessa lei municipal, definindo a atuação do legislador na escolha das prioridades em políticas públicas urbanas.

Com isso, todo cidadão pode participar dos processos relevantes de deliberação e decisão na formação do sistema normativo, sempre nos termos de uma liberdade comunicativa, em que a posição de cada um possa ser avaliada de maneira igual.

Desta forma, dever-se-á garantir a todos iguais direitos políticos fundamentais, para que o povo exerça sua soberania através e a partir de uma formação discursiva da soberania e da vontade. A institucionalização jurídica das técnicas discursivas é uma forma de legitimar a própria normatização jurídica.

Na linha do que foi exposto, é possível afirmar que a autonomia no âmbito privado é necessária para garantir uma autonomia no âmbito público, uma vez que apenas a autonomia privada pode garantir a liberdade de igual participação no processo político democrático (formação discursiva das decisões políticas). Assim, a teoria discursiva une o ambiente privado ao público, garantindo e estabelecendo um diálogo entre o destinatário da política pública e o seu autor.

16 HABERMAS, Jürgen. Ob. Cit. P. 159 - 160. 
Com isso, a legislação urbanística estabelece um espaço público dialógico, institucionalizando procedimentos participativos que permitem ao cidadão atuar nas decisões políticas, outorgando legitimidade diante do consenso firmado. Nesta toada, após a formação do consenso a atuação estatal deixa de ser discricionária e passa a estar vinculada aos termos da convergência de vontades pré-estabelecidas. O respeito ao consenso criado deve ocorrer não apenas por parte dos entes envolvidos, mas também, por parte de todos os atores estatais.

\section{CONCLUSÃO}

A regularização fundiária como um dos pilares das políticas públicas urbanas demonstra que o legislador reconhece a situação de informalidade dos diversos assentamentos urbanos no Brasil e a importância de sua regularização. Além disso, o histórico apresentado demonstra que tal preocupação já tem espaço na agenda política nacional há décadas, confirmando a robustez da produção legislativa acerca do tema e sua relação direta com o processo de urbanização brasileiro.

Os dados do Ministério das Cidades sobre o déficit de moradias no Brasil confirmam a importância da inserção dos assentamentos informais na lógica da regularização fundiária. A precariedade da relação jurídica do ocupante com o bem ocupado (público ou privado) é fator que intensifica o deslocamento desse morador no território. Dessa forma, a regularização fundiária fortalece a relação do ocupante com o bem ocupado, outorgando-Ihe uma série de garantias e preservando o seu direito em permanecer na coisa.

Não restam dúvidas de que a Lei 13465/2017 alterou de forma substantiva o sistema de regularização fundiária no Brasil, como brevemente demonstrado no decorrer do texto. $O$ afastamento da exigência acerca da participação popular no desenvolvimento de políticas públicas urbanas, com a revogação de parte da Lei 11977/2009 pela Lei 13465/2017, tem o objetivo de desburocratizar o processo, intensificando a discricionariedade estatal.

No que tange a regularização de assentamentos informais na área ocupada, a participação desses ocupantes é o principal elemento que pode outorgar legitimidade a atuação do Poder Público. Tal participação é imposta diretamente pela Lei 10257/2001, norma regulamentadora dos artigos 182 e 183 da CRFB/88, independentemente de inserção expressa no novo marco legal de regularização fundiária, a Lei 13465/2017.

A referida conformação democrática deve avaliar, por exemplo, qual instrumento deve ser aplicado aquela determinada regularização, a forma como o mesmo será outorgada, individual, coletivo, transmissível, intransmissível, qual destinação que o ocupante poderá outorgar, entre outras determinações. 
A partir dessa linha de análise, a discricionariedade da administração pública na realização de políticas urbanas de regularização fundiária é preservada, mas a sua legitimidade depende da participação popular, especificamente dos destinatários da política, na tomada de decisão. Apenas com a partir de uma lógica democrática que a política de regularização conseguirá aderência social e resultado efetivo.

A regularização fundiária desenvolvida nesses termos garantirá a fixação substancial do ocupante no território. O deslocamento arbitrário dos ocupantes de assentamentos urbanos consolidados atua para formação de um ambiente urbano segregado, afastando dos locais de infraestrutura àqueles que estão em uma situação de informalidade. Desta forma, a opção pelo sistema mais adequado deve levar em conta a diminuição da intensidade desses deslocamentos.

\section{REFERÊNCIAS}

BUCCI, Maria Paula Dallari (Org.). Políticas Públicas: reflexões sobre o conceito jurídico. O Conceito de Política Pública em Direito. 1a. Ed. São Paulo: Saraiva, 2006.

CARVALHO FILHO, José dos Santos. Manual de Direito Administrativo. 21a Ed. Rio de Janeiro: Lumem Juris, 2008.

DAL BOSCO, Maria Goretti. Discricionariedade em políticas públicas. Capítulo III. Curitiba: Juruá, 2008.

GARCIA, Maria (Org.). A Cidade e seu Estatuto. A Cidade e o Estado, Políticas Públicas e o Espaço Urbano. 1a Ed. São Paulo: Editora Juarez de Oliveira, 2005.

HABERMAS, Jürgen. Direito e democracia: Entre facticidade e validade, Volume I. 2ª Ed. Jürgen Habermas; tradução Flávio Bueno Siebeneichler. Rio de Janeiro: Tempo Brasileiro, 2003.

LUFT, Rosangela Marina. Políticas Públicas Urbanas: Premissas e condições para efetivação do Direito à Cidade. Parte II, Capítulo I - A cidade enquanto direito à função social. 1a Ed. Belo Horizonte: Editora Fórum, 2011.

OSÓRIO, Letícia Marques. Direito à Moradia adequada na América Latina. In: FERNANDES, Edésio; ALFONSIN, Betânia. Direito à moradia e segurança da posse: diretrizes, instrumentos e processo de gestão. 1ạ Ed. Belo Horizonte: Fórum, 2004.

MARICATO, Ermínia. Impasses da Política Urbana no Brasil. 1ạ Ed. Rio de Janeiro: Editora Vozes, 2011.

MEIRELLES, Hely Lopes. Direito Administrativo Brasileiro. 26ạ Ed. São Paulo: Malheiros, 2001.

RICALDE. Maria do Carmo. Regularização Fundiária Rural e Urbana: Impactos da Lei 13465/2017. 1a ed. Campo Grande: Contemplar, 2018. 